\title{
Peña Freire, Antonio Manuel. Legalidad y orden jurídico. El debate sobre la legalidad del exterminio Nazi. Atelier, Barcelona, 2018.
}

\author{
Manuel Salguero \\ Universidad de Granada
}

Fecha de recepción 17/10/2018 I De publicación: 24/12/2018

El contexto académico en que se ha gestado este libro del Profesor Antonio Manuel Peña Freire, reavivando el necesario impulso durante cinco años como se desvela en el muy esclarecedor capítulo de agradecimientos, ya augura un resultado muy satisfactorio. Es sintomático que inicie su discurso enfatizando que la idea de derecho ha permanecido oscura incluso a los ojos de sus principales estudiosos. Esta consideración va en la línea de lo que, según Aristóteles, caracteriza a la filosofía: un saber peculiar que anda siempre tras la búsqueda de su propio objeto de conocimiento. Kant ahonda en esta misma idea al aseverar que los filósofos del Derecho están siempre preguntándose acerca de qué es Derecho. Me parece relevante esta apreciación porque el autor de este libro hace explícito el presupuesto de que al examinar el debate sobre la legalidad del exterminio Nazi se dilucida, también, la cuestión ontológica sobre la definición del Derecho. A este presupuesto se vincula otro que, según mi apreciación, se hace presente a lo largo del libro, aun sin expresarlo explícitamente. Se trata de la cuestión del positivismo ideológico con los diferentes ingredientes que se asocian a la legalidad positivizada. Se cuida, al respecto, nuestro autor de decir que no puede identificarse la idea de derecho y de justicia, y que no todo el derecho es justo por definición "ni nada parecido" (p. 13 del texto citado). Se rechaza, por tanto, un positivismo ideológico en su sentido más estricto, cuyo representante más originario es el Leviathan hobbesiano, si bien no parece poder excluirse un cierto positivismo ético o inclusivo, dado que -según dice el Profesor Peña- la legalidad - que es uno de los aspectos centrales de la idea de derecho- "es expresiva de un bien moral" (p. 13). Se trata de ver -y a ello dedica su empeño este libro- qué valor tiene la legalidad del derecho en su positividad. El camino para esclarecer esta compleja cuestión de la moralidad de la legalidad lo encuentra nuestro autor en la necesaria dilucidación de la idea misma de legalidad que adquiere su auténtica dimensión constitutiva cuando sea el resultado de haber asumido la moral interna del derecho. Este reducto de la moralidad de la legalidad es lo que lleva a nuestro autor a considerar que la legalidad es incompatible con prácticas exterminadoras o genocidas como fue el caso del Holocausto Nazi. 
Encontramos en este libro un loable afán epistemológico por delimitar y precisar los términos en que se desenvuelve el trabajo investigador. Al mostrar los diferentes enfoques y las distintas posiciones de muchos e importantes autores (Lon Fuller, H.L.A. Hart, Radbruch, Raz, Waldron, Fraser, Gardner, Campbell, Kramer, Simmond, Dyzenhaus, Rundle...) que configuran los variados registros del debate, nuestro autor incorpora un ajustado tratamiento del método de las "quaestiones disputatae" del clasicismo en su mejor expresión. El autor de este libro maneja, en efecto, con habilidad los instrumentos metódicos que ofrece la técnica de la disputa y de la controversia, y todo ello para aquilatar - tras la pugna del arduo debate y una vez examinados los argumentos a favor y en contra- la propia posición conclusiva fundamentada: "legalidad y exterminio son incompatibles", aunque muchos operadores jurídicos han sido responsables de brutales matanzas; "la legalidad y el derecho bien entendidos no son herramientas apropiadas para materializar las matanzas del genocidio Nazi, y "Auschwitz no es el paradigma de un espacio pleno de derecho ni jurídicamente constituido (...) sino la antítesis de la legalidad y de lo que un orden jurídico representa" (p. 27).

Nuestro autor tuvo la ocasión propicia de practicar la meticulosidad indagatoria que exigen los términos de este debate ético-jurídico, intramuros de la Universidad de Toronto, en su fructífera estancia de investigación, como nos sugiere en su ya citado capítulo de agradecimientos. Llego a imaginar al profesor granadino casi enclaustrado -como aquellos estudiosos medievales- en su bien nutrida biblioteca y con el sosiego necesario (tan poco frecuente en nuestros días) que exigen la indagación y la reflexión. Lo que hay de escolasticismo y de sabor a lo clásico en las páginas de este libro lo atribuyo yo a este contexto académico, alejado de ruidos y premuras.

Al adentrarse nuestro autor en las patologías jurídicas del exterminio Nazi, hay que destacar su importancia clínica con vistas a indagar en la idea de derecho, así como analizar los perfiles de la legalidad. En esta ardua tarea, el profesor granadino se nos muestra rodeado de algunos monstruos, que necesitan un poderoso cancerbero, como si se tratara de un retorno a aquel mítico y proceloso estrecho marino entre Escila y Caribdis. Pero ahora, y más en concreto, el Doctor Peña surca su discurso entre Leviathan y Beemoth, dos poderosos monstruos, de los cuales el segundo, un monstruo de la tierra, es referido en el libro de Job (38-41) y a quien San Agustín tomó por Satán. Fue Hobbes quien popularizó a ambos, representando Leviathan la idea de un estado político de coerción, en el que -como dice Franz Neumann (Behemoth..., Anthropos, 2014, p. XIX) en su "Nota sobre el nombre de Behemoth" - aun quedan vestigios del imperio de la ley y de los derechos individuales. Este monstruo del mar, 
Leviathan, es quien -en tanto que el Soberano- establece la ley justa, identificándose entonces positividad legal y justicia, que es la más genuina expresión del positivismo ideológico. Pero es más bien frente a Behemoth ante quien se ubica el Profesor Peña, es decir, ante este otro monstruo del caos que se ha tragado por completo la dignidad de los seres humanos. Behemoth se nos muestra como el verdadero rostro del Holocausto en el sistema nacional-socialista de Hitler del que asevera Neumann que fue "un monstruo caótico, amorfo y sin ley". Esta disyuntiva entre Leviathan y Behemoth queda expresada por el profesor granadino (pp. 242-246) cuando acude a la cabalística numérica de 1492 (los Decretos de Granada sobre la expulsión de los judíos, dictados por los Reyes Católicos) y de 1942 (Las resoluciones adoptadas en la Conferencia de Wannsee en donde un grupo de dirigentes nazis y altos funcionarios acordaron secretamente los términos para proceder a la "Solución Final" del problema judío). Es cierto que se siente incómodo el profesor granadino y que no le satisface tener que admitir que con los Decretos de 1492 se produce un orden jurídico de legalidad por el que los judíos fueron expulsados. Es un resultado no deseable e injusto pero, al menos, esa injusticia es "legal". Es decir, la expulsión se hace compatible con la legalidad. Pero en el caso de 1942 esas resoluciones que marcan la "Solución Final" (p. 209) no constituyen ya un orden jurídico de legalidad porque la política de exterminio hizo que decayera definitivamente la legalidad. O dicho de otro modo, el Holcausto se hizo posible porque la legalidad se degradó definitivamente y quedó totalmente cancelada. Los judíos dejaron de ser sujetos de normas y pasaron a ser objeto de exterminio. Este es el rostro de ese otro monstruo: Behemoth. El Holocausto se hace incompatible con la legalidad. Si se hubieran mantenido las condiciones de legalidad los judíos no habrían sido exterminados y si lo fueron se debió a la cancelación total de la legalidad. Un exterminio legal es imposible. La injusticia es, en este caso, una injusticia "ilegal".

Estas convicciones que sostiene el Profesor Antonio Manuel Peña (en los breves capítulos 5 y 6 ) son preanunciadas desde el inicio mismo de su indagación y se van desgranando aquí como necesarios corolarios. Estaba preanunciada la tesis, pero hacía falta un amplio periplo para organizar el andamiaje epistemológico y buscar la adecuada senda para estar bien pertrechados frente al temible Behemoth, y también frente a Leviathan.

Este amplio periplo epistemológico -que conduce hacia estas convicciones- se encuentra especialmente en los capítulos 3 y 4. En el capítulo 3 (ocupa buena parte del libro, páginas 47-150) se muestra como alternativa la posibilidad de concebir a los órdenes jurídicos como un conjunto de relaciones de 
legalidad más bien que como un conjunto de normas. En el capítulo 4 se hace una indagación sobre la moralidad de la legalidad y de los órdenes jurídicos para poder sostener que las prácticas de exterminio y el Holocausto no pueden figurar en la denominación de injusto jurídico.

La cuestión acerca de cuánto de inicuo o insoportable es un derecho para ser eliminado como derecho queda mejor resuelta -siguiendo a Lon Fuller a quien rescata Antonio M. Peña como eje del debate de la moralidad de la legalidad - si se presta la adecuada atención a los principios de la legalidad: generalidad, publicidad, prospectividad, inteligibilidad, coherencia, posibilidad, estabilidad y congruencia (véase pp. 72 y ss.). De lo que se trata, según nuestro autor, es de indagar, con mayor solvencia, que la legalidad es un fenómeno intrínsecamente moral (p. 41). Aquí dice haber hallado un filón digno de ser trabajado para adentrarse en la riqueza prometedora que encuentra en las tesis matriciales $-\mathrm{y}$ no suficientemente elaboradas- de Fuller. A partir de este hilo proteico se diseña el aparato epistemológico de los capítulos 3 y 4 para establecer después su posición en los capítulos 5 y 6 .

Desde una aproximación socio-antropológica del Derecho que cuestiona la centralidad de rasgos tales como el monopolio del uso de la fuerza, se propugna una noción de orden social en donde no todo es orden jurídico y entendiendo el orden jurídico como un orden de legalidad. Nuestro autor se pregunta como cuestión primordial por la moralidad de la legalidad (pp. 151 y ss.) y en este sentido muestra su querencia por el positivismo ético que percibe como referente en Fuller y en autores como Campbell o Waldron, entre otros. Está convencido nuestro autor de que sobre la moralidad de la legalidad hay que adoptar una perspectiva o actitud distinta de la que habitualmente subyace a la confrontación entre iusnaturalismo y iuspositivismo normativista (véase pp. 159 y ss.). En apoyo del positivismo ético nuestro profesor granadino subraya las deficiencias de una lectura instrumental de la moralidad de la legalidad porque los principios de legalidad tienen una dimensión moral intrínseca. Pero esto no ha de llevar a adoptar una concepción sustancial de la legalidad que la equipare con la idea de justicia, sino a una teoría que busque las dimensiones morales de la legalidad (p. 171). La legalidad incorpora implícitamente dimensiones morales valiosas al orden jurídico, independientemente de los fines que se persigan conforme a esos principios de legalidad. También R. Dworkin (Hart's Postscript) considera, en este sentido, que la legalidad es realmente un valor específicamente jurídico. No se trata de identificar, sin embargo -según nuestro autor- legalidad y justicia sino de afirmar que la teoría de la legalidad es en sí misma una teoría de la justicia. 
El derecho es, por tanto, "un método para la ordenación social que está necesariamente conectado con la moral porque contiene principios morales entre sus elementos constituyentes" (p. 172). No hay que preguntarse con qué moral está conectado el derecho sino "por la moral en que consiste el derecho". La dimensión moral de la legalidad se remite a unos principios morales constitutivos de dicha legalidad (limitación del gobernante, libertad, capacidad para la autodeterminación del individuo, dignidad, interacción social, reciprocidad) más allá de una interpretación instrumental (pp. 171 y ss.). El derecho está necesariamente conectado a estos principios morales constitutivos de la legalidad. Son parte del ideal de justicia pero que no la agotan. Esto quiere decir que para hablar de orden jurídico no es necesario que se dé un grado máximo de legalidad o que haya una realización perfecta de la idea de legalidad. Puede haber un grado satisfactorio de legalidad, un grado de deterioro compatible con la legalidad, un grado de deterioro incompatible por insuficiente o un grado de deterioro total (pp. 201 y ss.).

En relación con este posicionamiento que hace el Profesor Peña a favor de un positivismo ético o de un inclusivismo moral, cabe preguntarse si es posible evitar caer en el positivismo ideológico. Si en la legalidad anidan principios morales que le son intrínsecos, dicha legalidad, por el solo hecho de su positividad, ya tiene un valor moral o una cierta expresión de lo justo. Ciertamente el positivismo ideológico no podrá ser tomado aquí en sentido fuerte (identificación entre lo legal, por su sola positividad, y la justicia), pero sí podría decirse que habrá que tomarlo en sentido débil de manera inevitable. Esto ocurre, por ejemplo, también, en H.L.A. Hart con su idea del contenido mínimo del derecho natural con respecto al cual existe una conexión necesaria entre derecho y moral. Por eso, cabe preguntarse por la diferencia sustancial existente entre la moral interna del derecho de que habla Fuller (inner morality of law) y ese contenido mínimo del derecho natural de Hart.

Como decía, todo este andamiaje epistemológico que acabamos de destacar es utilizado por nuestro autor como fundamento al que se anudan como sindéresis las conclusiones de los dos últimos capítulos.

Para hacer ver la proyección que tiene el libro que reseñamos, y para apreciar cuán extensa, abierta o problemática resulta ser esta idea de la moral interna del derecho, del inclusivismo moral o del positivismo jurídico incluyente $-\mathrm{y}$ sus implicaciones con el iusnaturalismo y con el positivismo jurídico- podrían considerarse las aportaciones, entre otros muchos, de autores como W.J. Waluchow (Inclusive Legal Positivism, Clarendon Press, Oxford, 1994). En un escenario más próximo, pueden anotarse algunos estudios en El caballo de Troya del positivismo jurídico (Juan B. Etcheverry, P. Serna 
ed., Comares, Granada 2010). Muy recientemente Andrés Ollero Tassara ha destacado aspectos sustanciosos, en este sentido, al hacer una extensa reseña (Eunomía. Revista en Cultura de la Legalidad, $\mathrm{n}^{\mathrm{o}} 15$, octubre 2018, pp. 335-346) al libro reciente de Lorenzo Peña: Visión lógica del derecho: Una defensa del racionalismo jurídico (Plaza y Valdés, Madrid 2017). Manteniendo su discrepancia con el iusnaturalismo de J. Finnis (sigo las apreciaciones de Ollero), Lorenzo Peña aboga por un iusnaturalismo que gira en torno al "imperativo del bien común" y al que denomina "iusnaturalismo aditivo", que no resta nada al derecho positivo sino que le añade la obligatoriedad del bien común y la no arbitrariedad. Estos imperativos constituyen la esencia misma del ordenamiento jurídico y la razón de su existencia. Con respecto a esa consecución del bien común, hay grados o niveles de aproximación, como ocurre, también, con los principios de legalidad en el libro de Antonio Manuel Peña. Podríamos, en fin, preguntarnos -y tal vez lo haya hecho nuestro autor- si, al hilo de lo que hemos reseñado, sigue teniendo vigencia aquel tópico de Rommen sobre el eterno retorno del Derecho Natural en alguna de sus metamorfosis.

Finalmente, el libro que sucintamente hemos reseñado merece ser tenido en cuenta por el rigor académico que lo caracteriza, por la exégesis doctrinal que se elabora, por las convicciones sostenidas metódicamente, y por insertarse en un debate impregnado de complejidad con mucha proyección hacia el futuro.

Por razones que trascienden lo académico, me adhiero al sentido homenaje que Antonio Manuel Peña hace a José Luis Serrano, amigo común y muy apreciado compañero, con ocasión de este libro. 